\title{
INTERDISCIPLINARY AND INTERSECTORAL DOCTORAL EDUCATION DESIGNED TO IMPROVE GRADUATE EMPLOYABILITY
}

\author{
Tara Cusack ${ }^{1}$, Nicola Mountford ${ }^{2}$, Minna Isomursu ${ }^{3}$, Guido Giunti Garcia ${ }^{3}$, \\ Dimitris Filos ${ }^{4}, \&$ Ioanna Chouvarda ${ }^{4}$ \\ ${ }^{I}$ School of Public Health, Physiotherapy and Sports Science, University College Dublin, (Ireland) \\ ${ }^{2}$ School of Business, Maynooth University (Ireland) \\ ${ }^{3}$ University of Oulu (Finland) \\ ${ }^{4}$ Laboratory of Computing, Medical Informatics and Biomedical Imaging Technologies, \\ School of Medicine, Aristotle University of Thessaloniki, (Greece)
}

\begin{abstract}
Typically, less than half of doctoral graduates will be employed in academia immediately after graduation, with less than 10\%-15\% achieving a long-term academic career. This leaves $85-90 \%$ of $\mathrm{PhD}$ graduates seeking employment outside the academic setting, for example in industry and government. The objective of the CHAMELEONS study (CHampioning A Multi-sectoral Education and Learning Experience to Open New pathways for doctoral Students) is to develop innovative educational interventions that shape more adaptable, entrepreneurial, and employable graduates, ready to meet the challenges of the future. Stakeholders from the connected health industry, clinical care, charities, patients, patient representatives, government, recent doctoral graduates, and academics were invited to participate in a "World Cafe" participatory method for collecting qualitative data. Owing to the COVID-19 health situation this took place via Zoom. Analysis of the results revealed 4 key learning objectives for doctoral graduates to: 1. Develop networking and communication skills. 2. Understand user centred research design. 3. Market research capacity and research skills. 4. Build an understanding of themselves and others. This led to the development of three bespoke doctoral modules: 1. Forging relationships: Building and Sustaining your Doctoral Network; 2. Managing the Project: Keeping on Track with an Eye to the future; Module 3: Starting your Career: Future Proofing your Career and Getting a Job. These modules are available to doctoral students across five European Universities.
\end{abstract}

Keywords: Intersectoral, interdisciplinary, doctoral, education, participatory.

\section{Introduction}

Ten years from now, jobs will be more knowledge and skills-intensive than ever before. Demographic, socio-economic, and technological change together are having "a near-simultaneous impact on employment and need for new skill sets, requiring an urgent and concerted effort for adjustment" (World Economic Forum, 2016). Currently less than $20 \%$ of all doctoral graduates stay in academia with the remaining $80 \%$ seeking employment outside the academic setting, for example in industry and government (Euraxid, 2021). It would appear, therefore, that these graduates possess many of the required skills for purposeful employment outside academia. A gap has been identified, however, in that current doctoral curricula do not foster big thinkers and creative problem-solvers, graduate attributes that society needs (Bosch, 2018). There is a growing need to re-imagine a $\mathrm{PhD}$ education that incentivises doctoral students to engage with research consumers, not only within their discipline, but also, across other disciplines and sectors to have real social impact for an improved society. At a professional and research level, international, interdisciplinary and inter-sectoral networks are on the increase. Such collaborative doctoral programs can assist the knowledge society in finding innovative ways of approaching the world's problems by asking creative questions and finding creative solutions within multiple employment contexts (Mountford, Coleman, Kessie \& Cusack, 2020). To date, there is a lack of research in the area of the interdisciplinary, inter-sectoral doctoral education and the question remains: how do we best design these programmes to ensure that the $\mathrm{PhD}$ students' develop into big thinkers?

This paper presents the results of a module design process within the CHAMELEONS project (CHAmpioning a Multi-sectoral Education and Learning Experience to Open New pathways for doctoral Students). CHAMELEONS (2021) is a European Union Horizon 2020 research and innovation project which aims to design, deliver and evaluate a range of interdisciplinary, intersectoral and international modules that will broaden $\mathrm{PhD}$ graduate skills, improve their employability in both academic and non-academic environments and which will equip them to solve societal challenges in the area of 
connected health. CHAMELEONS was based upon previous work which examined the perceptions of interdisciplinary and intersectoral doctoral students engaged in EU funded Marie Curie Fellowships (Mountford et al., 2020) and the other which examined how interdisciplinary education could be used in the area of connected health (Chouvarda, Mountford, Trajkovik, Lončar-Turukalo, \& Cusack, 2019). The project consortium consists of ten partners from five European countries. Five are academic institutions, Maynooth University (Ireland), University of Oulu (Finland), University of Porto (Portugal), Aristotle University of Thessaloniki (Greece) and University College Dublin (Ireland). The remaining partners include an Irish non-profit patient representative organisation: Irish Platform for Patient Organisation Science and Industry), a Portuguese charity, Santa Casa da Miscericórdia da Amadora; a Spanish SME, Salumedia Labs; and a Spanish healthcare educator, the Andalusian School of Public Health.

\section{Objectives}

The overall aim of CHAMELEONS was to develop a range of interdisciplinary, inter-sectoral and international modules which are designed to broaden the skills of $\mathrm{PhD}$ graduates and improve their employability in academic and non-academic environments. The modules would enable students to develop fundamental and advanced research skills, business skills and knowledge while enhancing and further developing their emotional intelligence.

\section{Methods}

Stakeholders in the design process included representatives from the following: academia, industry, charities, health, patient representative organizations, expert patients, an education technologist, an expert in ethics, recent $\mathrm{PhD}$ graduates, and current $\mathrm{PhD}$ students.

The curriculum design workshop employed a "World Café" participatory design (Lo, Weinhardt $\&$ Sieber 2020). Under usual circumstances the design workshop would have taken place in a large room with a number of large round tables. The round table layout is considered to resemble a café. At each table there would be a nominated scribe, and this individual remains at the table throughout the workshop. Following discussion of the topic allocated to that table for the specified length of time the group moves to the next table. However, the scribe remains behind and updates the next group on the work already completed. The reasoning underpinning the rotation of the group is to build on the ideas and thoughts of the group which has gone before. This process enables a comprehensive discussion and debate of the issues at hand. Owing to the global pandemic it was not possible for this workshop to take place in a face-to-face environment, therefore breakout rooms in Zoom were used instead to mimic tables. In terms of the development/design workshop the groups within each table/breakout room were asked to focus on questions related to one of the following topics: Communication; Research Methods; Business Skills; Emotional Intelligence, Professional Development; Self-Care. These topics were chosen as they had emerged from a systematic literature review (Leniston \& Mountford, 2021) and surveys of current and recent doctoral graduates and doctoral programme coordinators (Kosvyra, Filos, Mountford, Cusack, Isomursu \& Chouvarda, 2021) all undertaken as part of CHAMELEONS. The workshop participants were asked to identify learning needs and strategies which might be used to achieve this learning. Data was recorded by each of the scribes and collated by the workshop lead. The data was categorised, examined and discussed at a series of smaller post workshop meetings. The purpose of this was to distill the essence of the workshop and to develop learning strategies mapped to the results of the workshop.

\section{Results}

Analysis of the workshop results revealed four desirable module learning outcomes. On successful completion of the module the students would be able to: 1. Develop networking and communication skills; 2. Understand ethical user centred research design; 3. Market their research capacity and research skills; 4 . Build an understanding of themselves and others. In order to address these learning outcomes the module was designed for delivery over five days with an intervening weekend. The module was entitled "Forging relationships: Building and Sustaining your Doctoral Network". Each day was dedicated to a particular topic and was led by one of the primary investigators in this project. Day 1 addressed communication; Day 2 Building Skills and Profile; Day 3 Understanding themselves and mapping their careers; Day 4 User centred design and Day 5 was a distillation of learning. Each day included interactive sessions which enabled students to network with potential employers, developing sessions relating to research skills, and personal development and reflection. The module will result in the award of five (5) European Credit Transfer System credits (ECTS). Assessment was designed to "fall from" the learning process whereby students presented their reflective learning together with developing a group presentation for delivery on the final day. The second and third modules, Managing the Project: Keeping on Track with an Eye to the future and Starting your Career: Future Proofing your Career and Getting a Job are currently being developed. They will be developed against the backdrop of previous work and the module one evaluation. 


\section{Discussion/conclusions}

This paper presents a framework by which stakeholders may come together to co-design a doctoral educational intervention. Co-created curricula are becoming increasingly important in a bid to keep pace with emerging new areas of employment for graduates across contemporary society. Engaging stakeholders is key to ensuring that doctoral education fosters the development of graduates who are "fit for purpose" in this fast-changing world. The skills attained during doctoral education, for example problem solving, project management, information literacy, innovation, entrepreneurship etc. are essential in a modern world seeking to be at the cutting edge of solving societal problems. Enabling graduates to create sustainable networks beyond their doctoral education is important for professional development.

Owing to Covid 19 travel restrictions the first module was rolled out via Zoom in April 2021. Discussion with the students on the final day of the module took place using Miro (an online collaborative tool https://miro.com). Following preliminary examination of student feed-back a number of key observations can be made. The students highly valued the opportunity to network and appreciated the speakers' and team's interdisciplinarity, despite the fact that it took place online. This may be heightened by the requirement to work remotely for over a year. The intervening weekend in the middle of the module proved to be important in order to give the students time to reflect upon their learning and begin to examine how their new skills could be integrated into their existing knowledge. The research skill development was highly valued. The module assessment (reflective submissions and end of module presentations) clearly demonstrated how the learning had enabled them to tap into and develop their emotional intelligence.

This project continues to develop, it is an iterative process underpinned by a systematic review conducted as part of the CHAMELEONS project, together with surveys of recent doctoral graduates and doctoral programme leads. The development continues to be informed by the students who participate in the module. CHAMELEONS continues to strive to meet its commitment to develop a range of interdisciplinary, inter-sectoral and international modules which are designed to broaden the skills of $\mathrm{PhD}$ graduates and improve their employability in academic and non-academic environments.

\section{Acknowledgments}

This project has received funding from the European Union's Horizon 2020 research and innovation programme under grant agreement No 873105.

\section{References}

Bosch G. (2018) Train PhD Students to be Thinkers not specialists. Nature 554, 277. Doi: 10.1038/d41586-018-01853-1

CHAMELEONS Consortium (2021) Retrieved April, 28, 2021 from https://www.chameleonsproject.eu/

Chouvarda I., Mountford N., Trajkovik V., Lončar-Turukalo T., Cusack T. (2019) Leveraging Inter-Disciplinary Education to secure the future of Connected Health Research in Europe. Journal of Medical Internet Research. 21 (11), e14020. doi:10.2196/14020

Kosvyra A., Filos D., Mountford N., Cusack T., Isomursu M., Chouvarda I. (2021) PhD courses and the intersectoral experience: a qualitative study. Paper for presentation at HEAd'21, Valencia, 2021 (In press http://headconf.org).

Leniston, N., and Mountford, N. (2021) Born or made - can interdisciplinary and intersectoral doctorate education create institutional entrepreneurs? A systematic review. Paper for presentation at HEAd'21, Valencia, 2021 (In press http://headconf.org).

Lo, K., Weinhardt, M., Siebe, S. (2020) The "World Cafe" as a Participatory Method for Collecting Qualitative Data. International Journal of Qualitative Methods. 19: 1-15. doi.org/10.1177\%2F160940692091697

Mountford, N., Coleman, M., Kessie, T., \& Cusack, T. (2020) Interdisciplinary doctoral research networks enhancers and inhibitors of social capital development, Studies in Higher Education, 45:12, 2558-2573. doi:10.1080/03075079.2019.1623768

Vitea Realising the Potential of Researchers. Euraxind. Retrieved April, 30, 2021 from https://www.vitae.ac.uk/researcher-careers/euraxess-uk-career-developmentcentre/euraxind/euraxind-project-background

World Economic Forum. (2016). The Future of Jobs, Global Challenge Insight Report, Retrieved April, 30, 2021 from http://www3.weforum.org/docs/WEF_Future_of_Jobs.pdf 